\title{
'Whatever it takes' to change beliefs: Evidence from Twitter
}

\section{Stiefel, Michael ${ }^{a}$ and Vivès, Rémi ${ }^{b}$}

${ }^{a}$ University of Zurich, Switzerland ${ }^{\mathrm{b}}$ Aix-Marseille Univ., CNRS, EHESS, Centrale Marseille, AMSE, France

\begin{abstract}
The sovereign debt literature emphasizes the possibility of avoiding a selffulfilling default crisis if markets anticipate the central bank to act as the lender of last resort. Motivated by the events of summer 2012 in the eurozone, this paper investigates the extent to which changes in beliefs about an intervention of the European Central Bank (ECB) explain the sudden reduction of government bond yields for the so-called PIIGS countries. To proxy beliefs, we study Twitter data from July to September 2012 and extract beliefs using machine learning techniques. Our results are consistent with the theoretical prediction that a central bank, which credibly commits to an intervention, can restore the fundamental "good" equilibrium.
\end{abstract}

Keywords: Self-fulfilling default crisis, unconventional monetary policy, Twitter data. 